Thorax, 1980, 35, 379-383

\title{
Sputum and blood concentrations of cefuroxime in lower respiratory tract infection
}

\author{
C W H HAVARD, R P BAX, T C SAMANTA, R M PEARSON, W BRUMFITT, J M T HAMILTON- \\ MILLER, AND C H DASH
}

From the Royal Northern Hospital and Royal Free Hospital, London, and Glaxo-Allenburys Research Laboratory, Greenford, Middlesex

\begin{abstract}
A detailed pharmacokinetic study of cefuroxime has been carried out. Levels of cefuroxime were determined in the blood, sputum, saliva, and urine of 23 patients receiving parenteral cefuroxime eight hourly for chest infections. Profiles were obtained after the first dose and on the final (fifth) day of treatment. Antibiotic levels in the sputum reached $0.8 \mathrm{mg} / \mathrm{l}$ within one hour of the first injection, and were maintained close to this value for six hours. There was a build-up by the fifth day, mean cefuroxime concentrations at this time reaching $1.8 \mathrm{mg} / \mathrm{l}$. This concentration was maintained for a prolonged period. Salivary concentrations were detectable but low (maximum mean value was $0.6 \mathrm{mg} / \mathrm{l}$ ). Concentrations of antibiotic were significantly higher in the serum than those observed after the same doses in volunteers. In the patients there was no build-up in serum levels between the first and fifth days. The data obtained explain the clinical efficacy of cefuroxime in the treatment of lower respiratory infections, and suggest that a 12-hour schedule may be feasible.
\end{abstract}

Cefuroxime is a new cephalosporin, very stable to $\beta$-lactamases and highly active against many pathogenic bacteria. ${ }^{1}$ Preliminary clinical studies have been encouraging, ${ }^{2}$ and we have found cefuroxime to be very effective in the treatment of infections of the lower respiratory tract. $^{3}$ During the course of the latter trial, we measured cefuroxime concentrations at numerous intervals in the sputum, saliva, and blood of the patients. Our results, reported here, help to explain why cefuroxime is effective in this type of patient.

\section{Patients and methods}

Twenty-three patients suffering from lower respiratory tract infections (13 bronchopneumonia, 10 acute exacerbation of chronic bronchitis) were treated with parenteral cefuroxime (Zinacef), thrice daily for five days. The pharmacokinetic behaviour of the antibiotic was studied in these patients during their treatment.

\section{PHARMACOKINETIC PROFILES}

The full profile involved taking blood at the following times after injection of the antibiotic: $0.25,0.5,0.75,1,1.5,2,3,4,5,6,7$, and 8 hours.

Address for reprint requests: Dr CWH Havard, Royal Northern Hospital, Holloway Road, London N7 6LD.
Table Details of pharmacokinetic profiles obtained

\begin{tabular}{lllll}
\hline Dose & $\begin{array}{l}\text { Route of } \\
\text { administration }\end{array}$ & $\begin{array}{l}\text { Number of } \\
\text { patients for } \\
\text { whom } \\
\text { profiles were } \\
\text { obtained } \\
\text { after both } \\
\text { first and } \\
\text { last doses }\end{array}$ & $\begin{array}{l}\text { Number of } \\
\text { patients for } \\
\text { whom } \\
\text { profiles were } \\
\text { abtained } \\
\text { after } \text { either } \\
\text { first or last } \\
\text { dose }\end{array}$ & $\begin{array}{l}\text { Total number } \\
\text { of profiles } \\
\text { obtained }\end{array}$ \\
& & 6 & 1 & \\
\hline $750 \mathrm{mg}$ & $\begin{array}{llll}\text { Intramuscular } \\
\text { Intravenous }\end{array}$ & 4 & 2 & 13 \\
$1.5 \mathrm{~g}$ & Intramuscular & 4 & 1 & 10 \\
Intravenous & 5 & 2 & 12 \\
\hline
\end{tabular}

Sputum was collected at the following times: 1, $1 \cdot 5,2,4,6$, and 8 hours. Sputum collection was preceded by collection of saliva samples. The patients then washed out their mouths and gargled with water before expectorating sputum. If sputum was difficult to produce, chest pummelling was performed. All urine passed during the eight hours after an injection was collected.

Ideally, profiles were taken from each patient after the first dose and after the last dose of antibiotic. However, in practice, full profiles were not obtained from every patient on both occasions. Details of the actual profiles obtained are shown in the table.

PROCESSING OF SPECIMENS

Blood samples were allowed to clot and the 


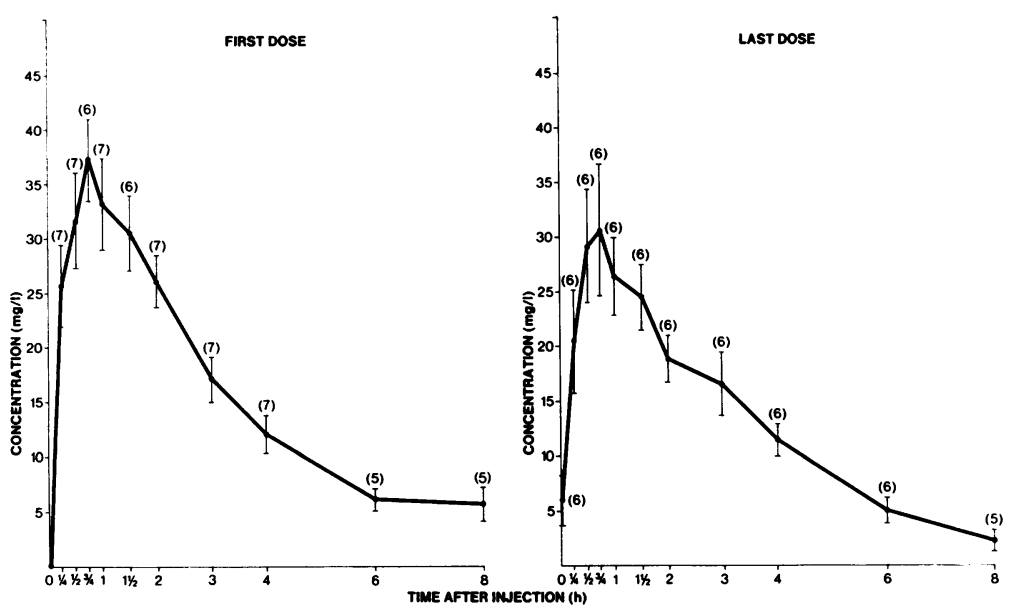

Fig 1 Mean concentrations $( \pm 1$ SEM) of cefuroxime in the $\overrightarrow{0}$ serum after (a) first and (b) last dose of $750 \mathrm{mg}$ given intramuscularly. (Number of samples indicated.)

serum separated by centrifugation. Each sputum sample was weighed, an equal volume of sterile saline added, and the mixture homogenised in a Colworth "Stomacher". Antibiotic concentrations in the various specimens were determined by biological assay, as described eslewhere. ${ }^{4} \mathrm{We}$ showed in a separate experiment that under the conditions described no deterioration in the cefuroxime level occurred.

The minimum detectable concentrations in serum and sputum or saliva were $0.63 \mathrm{mg} / 1$ and $0.13 \mathrm{mg} / \mathrm{l}$, respectively.

\section{Results}

\section{SERUM LEVELS}

The serum levels observed after the first and last doses of $750 \mathrm{mg}$ cefuroxime intramuscularly are shown in fig 1 . Mean levels were somewhat lower for the first three hours after the last dose compared with the same interval after the first dose, but this difference was not statistically $\vec{\circ}$ significant. Useful antibiotic concentrations were o still present in the serum eight hours after the injection.

It is interesting that serum concentrations were not higher after a dose of $1 \mathrm{~g}$ intramuscularlyo (fig 2) than after the smaller dose. However, it iso clear that the peak of the curve is much flatter, $\stackrel{\mathbb{Q}}{\circ}$ giving a plateau effect. This is reflected by the $\overrightarrow{\vec{O}}$ greater value of the parameter "area under 3 curve" for the profiles after $1 \mathrm{~g}$.

Profiles obtained after intravenous administration of cefuroxime are shown in fig $3(750 \mathrm{mg})$ and fig $4(1.5 \mathrm{~g})$. Serum concentrations were sub-을 stantially higher, and more prolonged, after the larger dose.

\section{SPUTUM LEVELS}

Our results on sputum obtained from patients

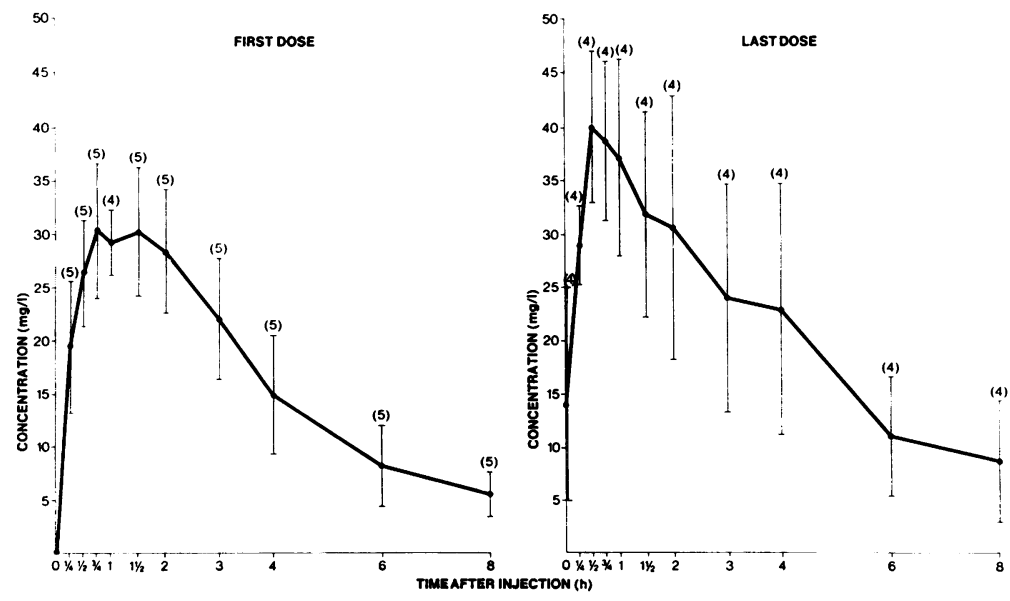

Fig 2 Mean concentrations ( \pm 1 SEM) of cefuroxime in the serum after (a) first and (b) last dose of $1 \mathrm{~g}$ given intramuscularly. (Number of samples indicated.) 

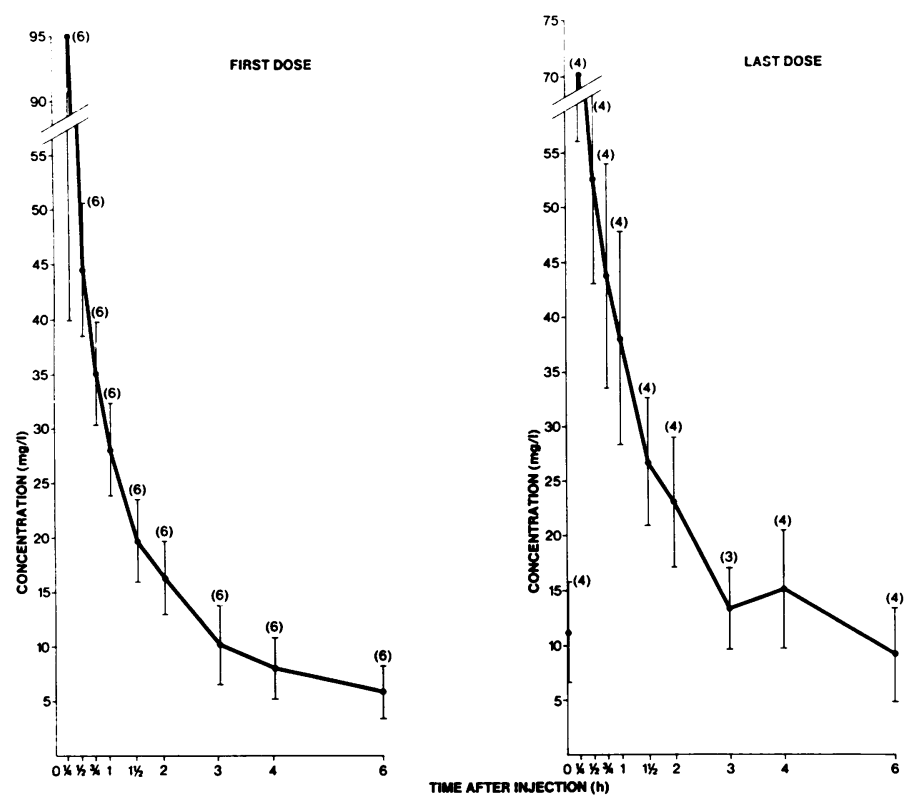

Fig 3 Mean concentrations $( \pm 1$ SEM) of cefuroxime in the serum after (a) first and (b) last dose of $750 \mathrm{mg}$ given intravenously (first dose: $n=6$; last dose: $n=4$ unless indicated otherwise).

treated with $750 \mathrm{mg}$ or $1 \mathrm{~g}$ cefuroxime intramuscularly are shown in fig 5 and 6 . In both cases, it is clear that a bactericidal concentration for the common pathogens in bronchitis ( $H$ influenzae and $S$ pneumoniae) is rapidly attained in the sputum. A notable feature is that there is a build-up effect during treatment, the concentrations after the last dose being significantly higher at one hour than at the same

time after the first dose. It is also very interesting that, once cefuroxime has entered the sputum, its removal is very slow. This is demonstrated by the fact that concentrations are virtually unchanged between three and eight hours.

\section{SALIVA CONCENTRATIONS}

These are also shown in fig 5 . They were always much lower than simultaneous sputum levels.

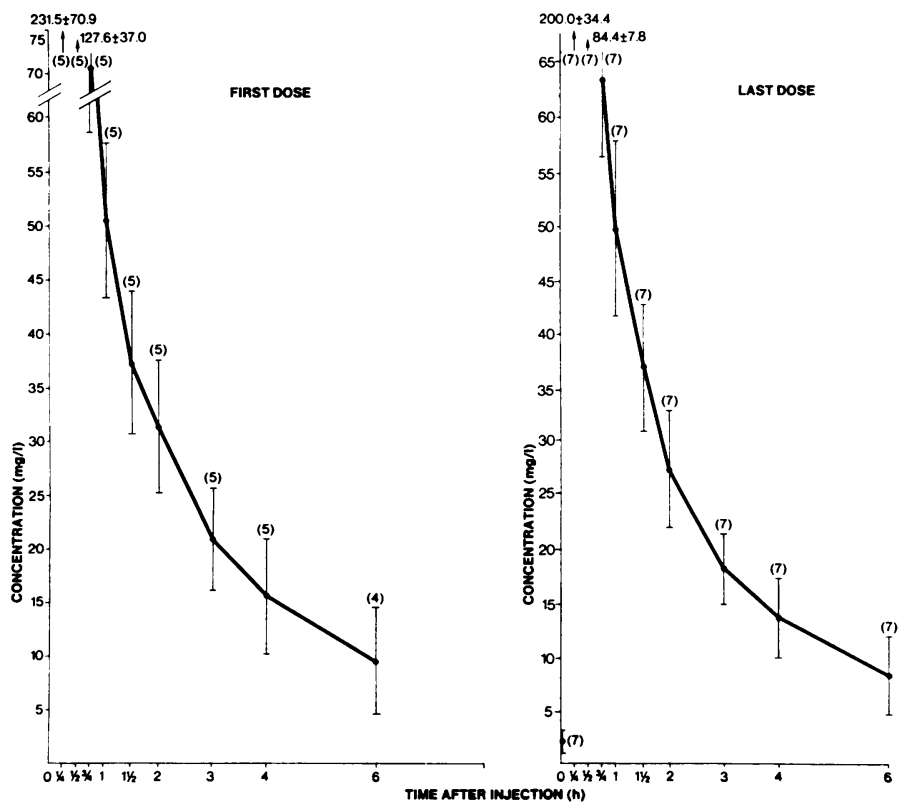

Fig 4 Mean concentrations $( \pm 1 S E M)$ of cefuroxime in the serum after (a) first and (b) last dose of $1.5 \mathrm{~g}$ given intravenously (first dose: $n=5$ unless indicated otherwise; last dose: $n=7$ ). 


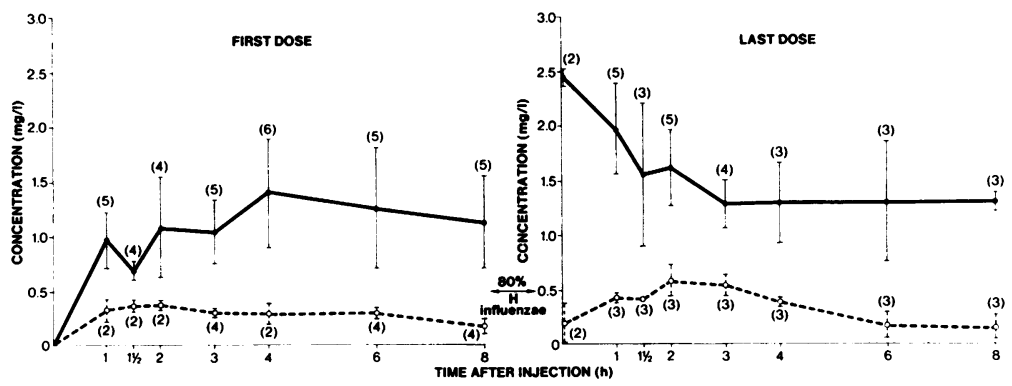

Fig 5 Mean concentrations ( \pm 1 SEM) of cefuroxime in sputum (—) and saliva $(\mathrm{O} \ldots$. . O) after (a) first and (b) last dose of $750 \mathrm{mg}$ given intramuscularly. Arrow shows concentration at which $80 \%$ of $H$ influenzae strains are inhibited in vitro. (Number of samples indicated.)

Peak concentrations $(0.4-0.6 \mathrm{mg} / \mathrm{l})$ were attained after about two hours, but there was a rapid falloff, to virtually nil after eight hours.

\section{URINE RECOVERY}

Complete 0-8 hours collections of urine were made on 41 occasions. There were no clear-cut differences in recovery after the various different doses and routes of administration. The mean overall recovery of cefuroxime was $57.6 \%$ $(\mathrm{SD}=25 \cdot 2)$.

\section{Discussion}

It is interesting to compare our results concerning serum levels of cefuroxime with those obtained in volunteers. After the $750 \mathrm{mg}$ intramuscular dose, we observed higher and more prolonged levels, with peak concentrations being reached slightly later, than did Foord ${ }^{5}$ and Nakagawa. ${ }^{6}$ Further, our figures are somewhat higher than those observed by Daikos et al, ${ }^{7}$ also in patients. We did not find increased peak concentrations after the $1 \mathrm{~g}$ intramuscular dose, but rather a plateau was observed in the concentration/time profile; Nakagawa ${ }^{6}$ obtained very similar findings in volunteers. Foord ${ }^{5}$ had earlier discovered that there was no proportionality for cefuroxime between the dose administered and the peak serum level, such as exists for other $\beta$-lactam antibiotics like ampicillin. ${ }^{8}$ There was no evidence of accumulation of cefuroxime on the currently adopted eight-hour dosage schedule.
An interesting finding here was that cefuroxime $\stackrel{x}{\dot{\omega}}$ disappeared from the serum more slowly than of previous experience in volunteers would sug- $\omega$ gest. ${ }^{56}$ This is presumably because our patients, $\circlearrowleft$ as a group, were elderly, and consequently would 은 be expected to have some degree of renal func- tion impairment. The rate of cefuroxime clear- 3 ance from the body is known to be affected markedly by changes in renal function. ${ }^{9}$ This $\vec{\bullet}$ notion is supported by our finding that only just ${ }^{\circ}$ over half the given dose of antibiotic was excreted within eight hours, in contrast to the virtually complete recovery in healthy volunteers. $^{56}$

There is little accurate information available $\frac{0}{\infty}$ on sputum levels of antibiotics. In our experience $\varnothing$ the ideal method for obtaining sputum for such $\overrightarrow{\overrightarrow{0}}$ a study is cricoid puncture but this has not yet 3 been used with cefuroxime. Bergogne-Berezon et $a l^{10}$ showed, in patients undergoing tracheostomy or fibreoptic bronchoscopy, that cefuroxime attains effective levels in the sputum $\frac{0}{N}$ earlier than other $\beta$-lactam antibiotics. If ex- $x$ pectorated sputum is assayed, as was done here, a $\frac{0}{3}$ prerequisite for accurate interpretation of results is knowledge of saliva levels. We have shown that the latter are not only low, but also fall away relatively rapidly, in contrast to the levels 5 in the sputum, which are well maintained during $\rightarrow$ the eight-hour interval between doses. The penetration of cefuroxime into sputum is clearly not $N$ related to the degree of purulence-levels were twice as high after five days of treatment, at

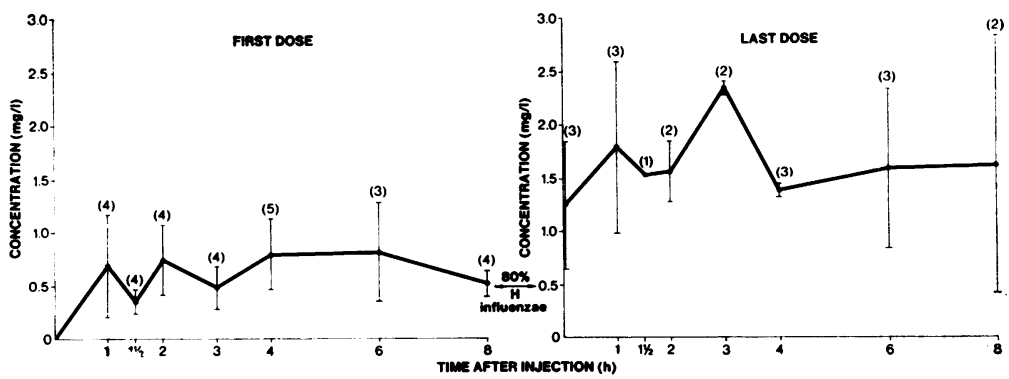

Fig 6 Mean concentrations $( \pm 1 S E M)$ of cefuroxime in sputum after (a) first dose and (b) last dose of $1 \mathrm{~g}$ given intramuscularly. Arrow shows concentrations at which $80 \%$ of $\boldsymbol{H}$ influenzae strains are inhibited in vitro. (Number of samples indicated.) 
which time sputum purulence had decreased markedly. ${ }^{3}$

May and Ingold" suggested that "the drug concentration in sputum is important in relation to the sterilisation of reservoirs of organisms from which relapse after treatment may stem, and that the highest attainable sputum concentration of ampicillin and amoxycillin was insufficient to inhibit all strains of $H$ influenzae, while the concentrations observed in many patients were too low to inhibit any strains." The second part of this statement certainly does not apply to cefuroxime: the mean sputum level achieved one hour after the first $750 \mathrm{mg}$ intramuscular dose is $1 \mathrm{mg} / \mathrm{l}$, which will be inhibitory for $H$ influenzae (MIC $0.5 \mathrm{mg} / 1$ ), $S$ pneumoniae (MIC $0.25 \mathrm{mg} / \mathrm{l}$ ), and penicillinase-producing staphylococci (MIC $1 \mathrm{mg} / \mathrm{l}$ ).

Our pharmacokinetic findings help to explain why cefuroxime is so effective in the treatment of lower respiratory tract infections. Its rapid penetration into; and slow excretion from, the sputum is clearly a very useful property in this respect. The persistence of cefuroxime in the sputum suggests that it may be possible to give the drug on a twice-daily schedule.

\section{References}

1 O'Callaghan CH, Sykes RB, Ryan DM. Muggleton PW. Cefuroxime: a new cephalosporin antibiotic. J Antibiot 1976; 29:29-37.

2 Glaxo Group Ltd. Cefuroxime. Proc R Soc Med
1977; 70: (suppl 9) 1-214.

3 Samanta TC, Bax RP, Pearson RM, Havard CWH, Brumfitt W, Hamilton-Miller JMT. Clinical study of cefuroxime in the treatment of lower respiratory tract infections. Curr Med Res Opin 1980; in press.

4 Glaxo Research Laboratories. The microbiological assay of cefuroxime. Proc $R$ Soc Med 1977; 70: (suppl 9) 195-6.

5 Foord RD. Cefuroxime: human pharmacokinetics. Antimicrob Agents Chemother 1976; 9: 741-7.

6 Nakagawa D. Phase one clinical study on cefuroxime. Proc $R$ Soc Med 1977; 70: (suppl 9) $22-4$.

7 Daikos GK, Kosmidis JC, Stathakis Ch, Giamarellou H. Cefuroxime: antimicrobial activity, human pharmacokinetics and therapeutic efficacy. J Antimicrob Chemother 1977; 3: 555-62.

8 Rolinson GN, Stevens S. Microbiological studies on a new broad-spectrum penicillin, "Penbritin". Br Med J 1961; 2:191-6.

9 Van Dalen R, Vree TB, Hafkenscheid JCM, Gimbrere JSF. Determination of plasma and renal clearance of cefuroxime and its pharmacokinetics in renal insufficiency. $J$ Antimicrob Chemother 1979; 5:281-92.

10 Bergogne-Berezin E, Even P, Bethelot G, Pierre J. Cefuroxime: pharmacokinetic study in bronchial secretions. Proc $R$ Soc Med 1977; 70: (suppl 9) 34-7.

11 May JR, Ingold A. Chronic respiratory infections. In: Amoxycillin Symposium. Amsterdam: Excerpta Medica, 1973: 326:130-4. 